\title{
Estado, descentralização e sustentabilidade dos governos locais no Brasil
}

\author{
Ailton Mota de Carvalho*
}

\begin{abstract}
In a historical moment in which political decentralization and greater importance of local government are subject of widespread interest, the lack of capacity of most Brazilian municipalities and cities to assume greater responsabilities is evident. This situation is easy to verify not only through the analysis of population, income levels and services sector data, but also because of the lack of minimum management and administrative skills by most municipal administrations in Brazil. The Brazilian case is explained by a historic process of municipalities creation which has been deformed in terms of principles and form by a shadow industry or cities creation. Therefore, the artificial creation of municipalities and cities jeopardizes the possibilities of successful government decentralization in Brazil.
\end{abstract}

Keywords: decentralization, local government, municipalities.

\section{Resumen}

En un momento en que se habla tanto acerca de la descentralización y la valoración de los gobiernos locales, se torna evidente la completa incapacidad de los municipios y de las ciudades brasileñas para asumir las crecientes responsabilidades que les están siendo confiadas. Esta incapacidad es fácilmente constatada a partir de datos objetivos de población, renta y prestación de servicios, pero también por la falta de capacidad de gestión y de preparación político-administrativa para el ejercicio de las mínimas funciones municipales. Dicha realidad brasileña está relacionada con el proceso histórico de municipalización, inicialmente distorsionado en sus principios y sus formas: una verdadera industria de creación de municipios y ciudades inviables que pone en peligro todo el proceso de descentralización y municipalización del Brasil.

Palabras clave: descentralización, gobiernos locales, municipalización.

\footnotetext{
* Universidade Estadual do Norte Fluminense. Correo-e: amota@uenf.br
} 


\section{Introdução}

Questionar, do ponto de vista teórico, o processo de reforma do Estado na América Latina é uma tarefa praticamente impossível, tal a força com que este modelo se implantou entre nós, a partir dos anos oitenta. Dentre os sagrados princípios dos programas de reforma, destaca-se a necessidade da descentralização da administração pública, com o repasse de deveres e obrigações dos níveis mais altos de governo, para os níveis mais baixos (no caso brasileiro para Estados e Municípios). Teoricamente, o que ampara o princípio da descentralização são os argumentos de que:

- Facilita a oferta diferenciada de bens e serviços;

- Melhora a identificação das necessidades;

- Melhora a capacidade para executar e controlar;

- Evita demandas excessivas;

- Diminuí custos e favorece a flexibilidade;

- Favorece a democratização;

- Favorece a transparência.

Este é o lado bom da descentralização e contra ele fica difícil argumentar, razão pela qual ele serve de estímulo para as emancipações municipais. Porém, para que a descentralização seja real, é preciso que o governo local, ou seja, o município, reuna as condições financeiras, administrativas e políticas para assumir as novas responsabilidades que lhes estão sendo confiadas.

Nos últimos dez anos, particularmente após o restabelecimento do regime democrático em 1985 e promulgação da nova Constituição Federal de 1988, o Brasil vem passando por um intenso processo de divisão política administrativa, materializada na fragmentação de sua malha municipal. Esta pulverização de novos municípios, de acordo com a estrutura político-administrativa brasileira, implica na criação direta do mesmo número de cidades, pois a passagem de um distrito para a condição de município, significa que o núcleo sede seja elevado à condição de cidade. ${ }^{1}$

Desta maneira, quando se cria um município inviável, significa também a criação de uma cidade inviável, ou não sustentável, pois não há como separar a parte do todo. Pelo contrário, todos os defeitos de origem são exacerbados e concentrados nas cidades, sobretudo se considerarmos a realidade de que a maior

\footnotetext{
${ }^{1}$ Por definição do Instituto Brasileiro de Geografia e Estatística (IBGE) toda a sede de município é uma cidade.
} 
parte da população brasileira vive nos centros urbanos, sedes de municípios. Por isso consideramos que o processo de emancipação municipal no Brasil é uma verdadeira indústria de criação de unidades inviáveis e insustentáveis, o que pode ser facilmente comprovado, verificando-se a situação de penúria econômica e de incapacidade de gestão da maioria dos municípios e cidades do Brasil.

Neste momento particular no qual se enfatiza a necessidade de sistemas mais descentralizados e se valoriza, por isso mesmo, o papel dos governos locais, dentro de uma concepção legítima de 'cidades sustentáveis', é preciso questionar e repensar um processo que, no caminho contrário, vem criando situações de inviabilidade econômica e administrativa.

\section{A proliferação de municípios no Brasil}

A criação de novos municípios no Brasil é uma prática antiga, que vez por outra desperta a atenção e a preocupação de alguns setores da sociedade, na medida em que se constata o exagero das políticas, e dando origem a interessantes matérias jornalísticas, com títulos sugestivos tais como "Municípios à míngua", "Farra das emancipações", "Pequenos falidos", "Febre das emancipações”. Uma pesquisa realizada pelo Banco de Dados Municipais do Instituto Brasileiro de Administração Municipal (Bremaeker, 1995), mostra que, na década de 1940 foram criados 315 novos municípios, na década de 1950 foram criados 877 , na década de 1970 surgiram mais 1,187 novas unidades municipais, e na década de 90 foram criados mais 1,007 novos municípios (quadro 1).

\section{Quadro 1}

Distribuição dos municípios instalados no Brasil (1940 a 1997)

\begin{tabular}{|c|c|}
\hline Anos & Número de Município \\
\hline 1940 & 1,574 \\
\hline 1950 & 1,889 \\
\hline 1960 & 2,766 \\
\hline 1970 & 3,952 \\
\hline 1980 & 3,991 \\
\hline 1991 & 4,491 \\
\hline 1993 & 4,974 \\
\hline 1997 & 5,498 \\
\hline
\end{tabular}

Fonte: Elaboraçao própria. 
Pelos números apresentados, vê-se que a criação de municípios não é nenhuma novidade na tradição política brasileira, caracterizando todo o período (1979-1980) mencionado. Verifica-se, também que durante o período do regime militar, esse processo diminuiu um pouco, voltando a intensificar-se a partir de 1990, com o restabelecimento dos governos democráticos.

Isto nos leva a levantar a tese de que é exatamente em períodos de mais abertura democrática e com eleições livres e diretas, que as oportunidades para os pedidos de emancipações municipais proliferam, demonstrando uma relação direta entre o processo eleitoral e o uso da bandeira da autonomia municipal como elemento de ação política. E mais que isso, as articulações de interesse no interior dos legislativos estaduais, o que explica a emancipação de muitos municípios que não atendem aos requisitos legais estabelecidos pelas próprias Assembléias Legislativas.

Esta dimensão política da emancipação municipal é evidente por si só, e tanto é assim que os pedidos de criação de novos municípios, mesmo submetidos a uma avaliação técnica preliminar dos órgãos estaduais competentes, terminam por uma aprovação (ou não) decidida pelos deputados estaduais.

O excessivo número de municípios no Brasil e, sobretudo a situação de penúria financeira dos mesmos, ensejou a proposta da Emenda Constitucional n ${ }^{\circ} 15$, de 12 de setembro de 1996, detalhada a seguir, com o objetivo de criar restrições ao surgimento de novos municípios (Bremaeker, 1996).

\section{A situação financeira dos municípios}

No afã de se criar novos municípios, a dimensão política da questão fala mais alto que a do aspecto financeiro. O resultado é a emancipação de municípios inviáveis, do ponto de vista econômico-financeiro, já desde as suas origens, e com todas as repercussões em cadeia que a falta de sustentação econômica provoca. As dificuldades financeiras por que passa a quase totalidade dos municípios, são mais que evidentes. Todos os dias, praticamente, encontramos, na mídia, notícias à respeito deste assunto. Citamos dois exemplos recentes ; "Municípios à Míngua" é a manchete do editorial do jornal Estado de Minas, de 19/09/99, no qual está citada a denúncia do Presidente da Associação dos Pequenos Municípios de Minas Gerais, de que 350 prefeituras mineiras de cidades de até 20 mil habitantes estão na eminência de fecharem as suas portas e paralisar todos os serviços, por falta de 


\section{dinheiro. "Pequenos e falidos ", é o título de uma matéria publi- cada na revista Veja de 7 de julho de 1999, que por si só já mostra a impossibilidade dos pequenos municípios de dependerem ape- nas de sua arrecadação.}

\section{Pequenos e Falidos}

Febre de emancipações cria municípios

Incapazes de viver da própria arrecadação

\section{Consuelo Dieguez}

Brasilândia do Tocantins é um município de pouco mais de 1.000 habitantes no norte do Estado. O lugarejo é tão pobre que a prefeitura não consegue arrecadar mais de 1.000 reais por ano. Ali não há hospital e os estabelecimentos comerciais registrados não passam de 25 . Apesar dessa situação de penúria, a Prefeitura de Brasilândia torra por ano, 330.000 reais só com pessoal. Outros 423.000 são gastos com despesas que vão desde a conta de água até o cafezinho para os funcionários públicos. A câmara de vereadores da cidade consome outros 103.000 reais. Se fosse depender apenas de sua arrecadação, a cidade não teria dinheiro para bancar sequer a conta de luz. Mas Brasilândia dispóe de uma tábua de salvação. Trata-se do Fundo de participação dos Municípios, um bolo de recursos dos governos federais e estaduais que, por lei, tem de ser dividido entre todas as prefeituras, com base na população. Nos últimos dez anos, esse fundo viabilizou a criação de centenas de municípios no Brasil. O que espanta é que cerca de 1.000 dessas novas cidadezinhas não tem a mínima condição de se sustentar sem os recursos do fundo.

Desde 1988, quando a nova Constituição facilitou as emancipações, os municípios não pararam de gerar filhotes. Todos de olho grande numa fatia de bolo. A constituição faz apenas duas exigências para a emancipação. Uma é que haja um plebiscito entre a população envolvida. A outra é que seja produzido um estudo de viabilidade. O problema é que esses estudos não se apegam a parâmetros financeiros sólidos. A pressão política dos mandachuvas locais fala mais alto. É por isso que o número de municípios saltou de 3.900 para os atuais 5.507 , a grande maioria com menos de 10.000 mil habitantes e arrecadação média anual inferior a 20.000 reais. É o caso de Oliveira de Fátima no Tocantins. O vilarejo foi alçado à condição de cidade em 1997, apesar de Ter apenas 754 habitantes. "Os estados deveriam Ter mais cuidado ao autorizar a criação de municípios", admite Jamil Reston, superintendente do Instituto Brasileiro de administração Municipal, ibam. "Mas boa parte dos exageros ocorre porque municípios mãe tratam seus distritos a pão e água".

Currais eleitorais - Em Quatis, no Estado do Rio de Janeiro, a situação não é muito diferente. A cidade, de 11.900 habitantes, vê escorrer pelo ralo da prefeitura 3,5 milhões de reais por ano. Só o funcionalismo consome quase dois terços do total. Elevada à condição de município no início da década, Quatis pouco conseguiu atrair para seu desenvolvimento. Os empregos são garantidos na vizinha Porto real - este, sim, um caso de sucesso dentro da febre das emancipações. Desmembrada de Resende há tr6es anos, Porto Real tem dentro do município uma fábrica de caminhões da Volkswagen que garante seu progresso.

"Os políticos estão tirando dinheiro dos municípios viáveis apenas para criar currais eleitorais", diz o senador Geraldo Althoff, do PFL de santa Catarina, autor de um projeto de emenda constitucional que estabelece critérios mínimos para que um distrito seja transformado em cidade. Pela proposta do senador, o distrito só poderá ser emancipado se comprovar que responde por, no mínimo, $10 \%$ da receita e abriga o correspondente a $40 \%$ dos moradores do município mãe. O que complica nas emancipações é que o bolo de recursos da União e dos Estados a ser dividido com os municípios continua do mesmo tamanho, mas as despesas duplicam. Cada novo município tem de criar uma prefeitura, um secretariado e mais uma câmara de vereadores. Haja dinheiro para tanta gastança.

Fonte: Revista Veja. 7 de julho,1999: 124 
É oportuno registrar que a Constituição de 1988 fortaleceu financeiramente os Municípios, porém, do ponto de vista legal, este fortalecimento se deu muito mais pela ampliação das transferências federais e estaduais, do que pelo lado das receitas tributárias municipais. A partir de 1989, os municípios passaram a receber $25 \%$ do ICMS (transferência estadual) (antes recebiam 20\%); e viram o Fundo de Participação (FPM) crescer de 17\% para 25.5\%. Como conseqüência, entre 1988 e 1998, a arrecadação municipal aumentou, elevando a participação dessa esfera de governo de $2.9 \%$ da carga tributária total para $5.3 \%$ (gráficos 1 e 2$)$.

\section{Gráfico1 \\ Evolução da receita tributária real $(1988=100)$}

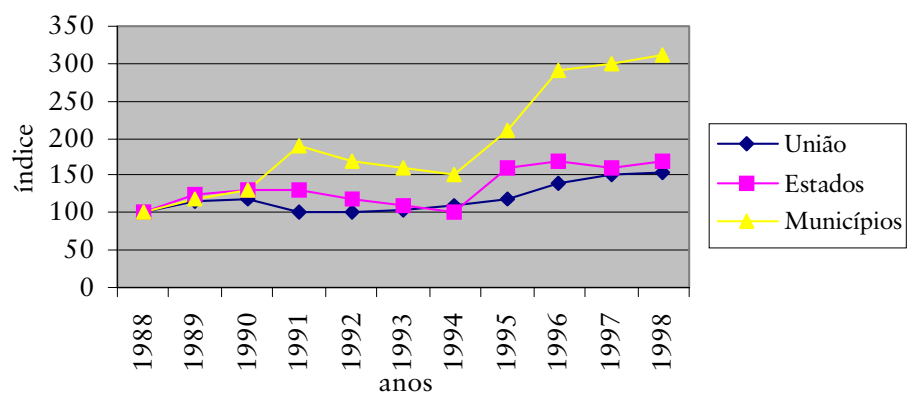

Fonte: Fundação Getúlio Vargas (2000).

Gráfico 2

Composição da arrecadação tributária por nível de governo (\% do total)

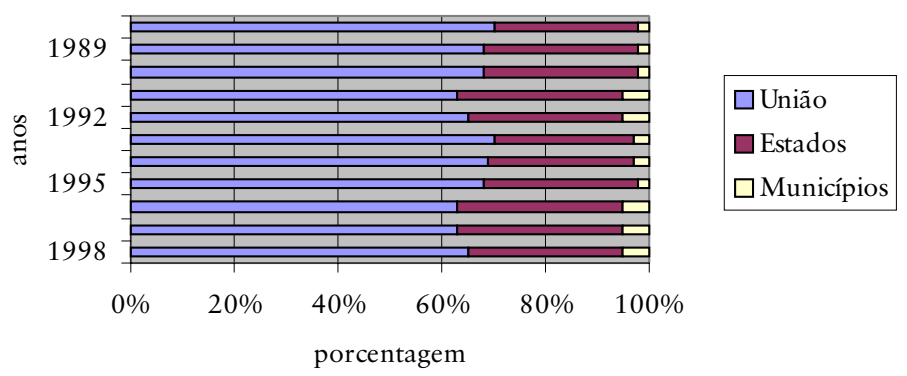

Fonte: Fundação Getúlio Vargas (2000). 
No caso das transferências, a grande tábua de salvação dos municípios é o FPM (Fundo de Participação dos Municípios) um bolo de recursos dos governos federais e estaduais que, por lei, tem que ser dividido entre todas as prefeituras, com base na população. Isto é verdadeiro, principalmente, para os municípios de pequeno tamanho (com população inferior a 10 mil habitantes) (Bremaeker, 1995).

Milhares de pequenos municípios e cidades do Brasil só sobrevivem graças ao Fundo de Participação dos Municípios. Como afirma o prefeito de Oliveira de Fátima, pequeno município do Estado do Tocantins, com 711 habitantes, "sem a verba do FPM a cidade pára”.

Estes pequenos municípios, geralmente de base econômica tipicamente rural, não possuem uma massa de contribuintes, quantitativamente e qualitativamente capaz de lhes possibilitar uma receita tributária expressiva. Além do mais diz Bremaeker: "os tributos que cabem ao Município cobrar são quase que todos de natureza tipicamente urbana (impostos sobre serviços (ISS); imposto predial e territorial urbano (IPTU); taxas e até mesmo a contribuição de melhoria). O único tributo que é aplicado tanto na área rural como urbana é o imposto sobre a transmissão de bens imóveis (IтВI)" (Bremaeker, 1996: 5).

Registra-se que para a maioria dos municípios brasileiros a arrecadação do IPTU e do ISs é difícil de ser realizada, pois demanda a constituição e atualização de cadastros de contribuintes e a contratação de pessoal altamente qualificado (quadro 2).

\section{Quadro 2}

Composição das receitas dos municípios (1996)

\begin{tabular}{|c|c|c|c|}
\hline Receitas & Capitais & Interior & Brasil \\
\hline Próprias & 58,5 & 27,7 & 38,1 \\
\hline ISS & 21,8 & 5,6 & 11,1 \\
\hline IPTU & 12,4 & 6,9 & 8,7 \\
\hline Outras & 24,3 & 15,2 & 18,3 \\
\hline Transferências & 41,5 & 72,3 & 61,9 \\
\hline ICMS & 28,7 & 39,4 & 35,8 \\
\hline IPVA & 6,0 & 3,0 & 4,0 \\
\hline FPM & 6,8 & 29,9 & 22,1 \\
\hline Total & 100,0 & 100,0 & 100,0 \\
\hline
\end{tabular}

Fonte: Fundação Getúlio Vargas (2000). 
Como se vê, fica evidente a enorme importância da rubrica 'transferências' na composição da receita municipal, destacando-se o FPM (transferência federal) e o ICMS (transferência estadual). Verifica-se, também, que esta estrutura de arrecadação privilegia os tributos urbanos o que, ao não funcionar, vai provocar o que estamos chamando de inviabilidade da administração das cidades, agravada pelo fato das mesmas concentrarem mais de $75 \%$ da população brasileira.

Frente a estes dados, surge de forma natural as seguintes perguntas: Por que isso acontece? Por que os municípios e cidades não conseguem arrecadar os recursos necessários e ficam dependendo de transferências dos outros poderes?

Bem, as explicações são várias. Em primeiro lugar a falta de vontade política de cobrar os tributos, na medida em que o 'imposto' é uma instituição culturalmente impopular no Brasil e a sonegação uma constante. Para os políticos populistas, rende muito mais dividendos eleitorais a isenção do que a cobrança de impostos, e não são poucos os exemplos deste tipo de atitude demagógica no Brasil. Outro fator devidamente reconhecido é a pobreza generalizada da população o que a torna relativamente incapaz de pagar tributos.

Acresça-se mais ainda a incapacidade administrativa das prefeituras para montar um sistema eficiente de arrecadação fazendária, com falta de pessoal especializado, falta de sistema de informática e falta de cadastros municipais atualizados e confiáveis.

De maneira mais ordenada e sintética podemos resumir assim estes fatores determinantes da atual situação econômicafinanceira dos municípios brasileiros:

- A tradição de uma 'economia de endividamento';

- Problemas relacionados à má gestão político-administrativa;

- O ritmo acelerado de inflação em que o país esteve mergulhado até meados de 1994, gerando perdas reais nos recursos públicos e uma cultura de orçamentos irreais;

- Baixo crescimento do PIB, restringindo a capacidade contribuitiva de pessoas físicas e empresas;

- Ajustes macroeconômicos do governo central, principalmente os relacionados ao déficit público, que através da criação de "fundos", como foi o Fundo Social de Emergência, e atualmente o Fundo de Estabilização Fiscal (FEF), subtrai receitas de transferências dos municípios; 
- O ambiente de incertezas que tem permeado as decisões de investimentos, inibindo uma retomada firme do crescimento econômico;

- A inexistência de políticas articuladas entre as esferas de poder, que assegurem um processo sustentado de desenvolvimento econômico;

- Os custos de implantação de um aparato fiscal moderno e eficaz.

Um outro fator que já foi mencionado linhas atrás, é que o sistema de arrecadação brasileiro é montado de tal maneira a permitir uma centralização em mãos do governo federal, mesmo após a Constituição de 1988. Sabe-se que na repartição da arrecadação tributária nacional, o governo federal tem cerca de 60\%; os governos estaduais cerca de $26 \%$; e os municípios apenas $14 \%$ em média. É fácil entender esta distribuição se considerarmos a história política brasileira, com uma prática centralizadora muito forte, apesar dos avanços de democratização mais recentes. Faz parte desta história e prática política, a barganha, que popularizou a norma do "é dando que se recebe" nas relações do executivo com o congresso nacional; e do poder central com os governos estaduais e municipais (quadro 3).

\section{Quadro 3 \\ Composição da receita tributária disponível por unidade de governo}

\begin{tabular}{|c|c|c|c|c|}
\hline Anos & Central & Estadual & Local & Total \\
\hline 1988 & 62,3 & 26,9 & 10,8 & 100,0 \\
\hline $1991-95$ & 57,0 & 27,3 & 15,7 & 100,0 \\
\hline 1996 & 56,5 & 26,6 & 16,9 & 100,0 \\
\hline 1997 & 56,3 & 27,1 & 16,6 & 100,0 \\
\hline 1998 & 56,5 & 26,7 & 16,8 & 100,0 \\
\hline
\end{tabular}

Fonte: Fundação Getúlio Vargas (2000).

Com relação a esta delicada e controversa questão da autonomia financeira municipal, é possível pensar que existe uma lógica implícita no comportamento da grande maioria dos pequenos municípios, guiada por um cálculo de custo e benefício, ou seja, o custo econômico e político para montar um sistema de arrecadação tributária é muito alto, frente ao que isso poderia representar em termos da arrecadação total do município. 
Ainda como ponto para reflexão deve-se ponderar se uma autonomia financeira e administrativa dos municípios, de acordo com a geografia e cultura política brasileira, seria viável, sem ameaçar o controle nacional sobre a gestão do seu território. Se partirmos da idéia de que a soma das partes não define o todo, neste caso, que a soma aritmética de municípios não definem o país, a hipótese fica evidente. Em outras palavras; qual seria o meio termo ideal entre um excesso de centralismo e uma proliferação de micro-unidades com a perda da unidade nacional? Talvez uma alternativa fosse a de revalorização do nível intermédio de administração (o regional) que foi tão importante em décadas anteriores.

Neste sentido de identificar alternativas intermediárias entre o nível central de administração e o nível local, merece lembrança a revalorização teórica e prática das 'cidades médias', o que tem relação direta com o modelo atual de descentralização político administrativa vigente em quase todos os países latinoamericanos e nos quais os chamados centros intermediários passam a desempenhar um papel determinante, enquanto espaços privilegiados de crescimento econômico e de aplicação de políticas de combate à pobreza e de sustentabilidade ambiental (Carvalho, 2000).

O fato é que a hegemonia do poder municipal no cenário atual tende a "homogeneizar a cotidianiedade", e o que é mais grave, devido aos efeitos desiguais que a globalização produz, a difundir a autonomia da pobreza (Carrión, 1999).

\section{A situação em Minas Gerais}

O Estado de Minas Gerais, que não foge a estas regras, é o nosso estudo de caso sobre o qual já tivemos a oportunidade de estudar a questão da viabilidade municipal em duas ocasiões. Como já foi feita referência anterior, em 12/09/96, o Congresso nacional, nos termos do parágrafo $3^{\circ}$ do art. 60 da Constituição Federal, promulgou a Emenda Constitucional $n^{\circ} 15$, dando redação ao parágrafo $4^{\circ}$ do art. 18 . Por essa emenda foi estabelecido em seu artigo único:

Artigo único. O parágrafo $4^{\circ}$ do artigo 18 da Constituição Federal passa a vigorar com a seguinte redação :

Art. 18. Parágrafo $4^{\circ}$. A criação, a incorporação, a fusão e o desmembramento de municípios far-se-ão por lei estadual, dentro do período determinado por lei complementar federal, e dependerão de consulta prévia, mediante plebiscito, às populações dos Municípios envolvidos, 
após a divulgação dos Estudos de Viabilidade Municipal, apresentados e publicados na forma da lei.

Minas Gerais é um estudo de caso peculiar, pois é o estado brasileiro que tem mais municípios : até 1960 tinha 485 unidades; em 1962 foram criados 237 novos municípios, totalizando 722 unidades; em 1992 este total subiu para 756 municípios; e em 1995 foi para 853 municípios.

A Lei $n^{\circ} 2,764$ de 30 de dezembro de 1962, foi a que criou a maior número de municípios, correspondendo a um aumento de cerca de 50\% sobre o total anterior. A criação de 237 novos municípios, num só ano, não se deu em função de algum eventual surto de urbanização que então estivesse ocorrendo no estado, mas sim em função do sistema de tributos partilhados que vigorava na época, com cotas iguais para todos os municípios. Assim, os governos Estaduais estimulavam a criação de novos municípios para arrecadar em mais recursos do Governo Federal.

A mentalidade dominante então, era a de que quanto maior o número de municípios para recorrer às fontes de recursos federais, tanto melhor, ainda que sem atender as condições legais para a emancipação.

Frente a essas circunstâncias, fica fácil deduzir que uma grande parte dos municípios foi emancipada precocemente, sem reunir as reais condições de viabilidade econômica, política e administrativa, como se demostrará a seguir. O mesmo se aplica, e com muito mais propriedade, às cidades, sedes municipais, onde vão desaguar todos os males decorrentes de um processo falseado.

\subsection{Os requisitos legais para a criação de municípios}

Como se mencionou, um dos princípios básicos para o processo de emancipação e criação de município no Brasil é a apresentação de um relatório de viabilidade, a ser definido por cada estado. Em Minas Gerais, de acordo com a Lei Complementar no $19 /$ 91, de 17/07/91, são necessários os seguintes requisitos para que um município seja criado:

i. População superior a 7,000 habitantes;

ii. Número mínimo de 3,000 eleitores;

iii. Número de moradias superior a 400 ; 
iv. Núcleo urbano constituído, com edificações para instalação do governo municipal, com seus órgãos administrativos;

v. Serviços públicos de comunicação, energia, água, posto de saúde, escolas públicas e cemitério;

vi. Arrecadação tributária mínima a ser anualmente fixada.

Não se trata, portanto, e de acordo com o espírito da lei, de uma emancipação meramente econômica-financeira mas, também, com população adequada, com infra-estrutura, e com um contingente de eleitores que possam viabilizar o processo político-eleitoral.

Em tese, portanto, os municípios que não atendessem a essas condições legais não deveriam ser criados, nem tampouco existirem. No entanto a realidade é bem outra. Com base em estudos que fizemos em 1985, atualizado com dados de 1992, podemos verificar e avaliar a viabilidade dos municípios mineiros, nesses dois momentos, com relação aos requisitos legais citados.

Fazendo um quadro comparativo entre os dois estudos mencionados, e considerando somente os itens de população, eleitores, moradias e arrecadação, temos a seguinte situação (quadro 4).

\section{Quadro 4}

\section{Minas Gerais-Municípios que não atendem aos requisitos} legais para emancipação

\begin{tabular}{|c|lr|rrr|}
\hline Requisito & \multicolumn{2}{|c|}{1985} & \multicolumn{2}{c|}{1993} \\
& $\mathrm{n}$ & \multicolumn{1}{c|}{$\%$} & $\mathrm{n}$ & \multicolumn{1}{c|}{} \\
\hline População & 415 & 57,5 & 299 & 41,3 \\
Eleitores & - & - & 136 & 18,8 \\
Moradias & 254 & 35,2 & 252 & 34,8 \\
Arrecadação & 459 & 63,0 & 63 & 8,7 \\
\hline
\end{tabular}

Fonte: elaboração própria.

A primeira observação que deve ser feita a respeito deste quadro é a de que em 1985 os requisitos não eram exatamente os mesmos de 1992 e que, comparativamente, eram mais rigorosos. Por exemplo: o número mínimo de população era de 10 mil pessoas e a arrecadação exigida era também superior, o que explica a diferença entre dados registrados para os dois anos.

$\mathrm{Na}$ realidade o que se observa com o passar dos anos é um aumento da liberalidade legal, com uma diminuição dos patamares dos requisitos legais, demonstrando uma prevalência dos critérios políticos sobre critérios técnicos, conforme já se mencio- 
nou em linhas anteriores. Relembre-se que a avaliação técnica geralmente é feita por um órgão da administração estadual, sem poder de decisão, o que acaba acontecendo depois de trâmites políticos, realizados nas Assembléias Legislativas que, via de regra, contrariam os pareceres técnicos. E mesmo que não fosse assim, as Assembléias Estaduais têm a prerrogativa de revogar as emancipações de municípios que, em algum momento, se mostrem inviáveis, o que, obviamente, é difícil de acontecer.

No caso específico da arrecadação, fator chave para o sucesso de qualquer administração local, deve-se registrar que no ano de 1992, o montante exigido correspondia a cerca de 6.5 salários mínimos da época, por ano, o que significa um orçamento que não cobre se quer o pagamento do pessoal necessário para a administração municipal.

Este é o quadro desolador da realidade da maior parte dos municípios brasileiros, emancipados sem critérios técnicos e a partir dele pode-se imaginar as inúmeras dificuldades administrativas das cidades e municípios, principalmente se considerarmos que muitos não atendem a nenhum dos requisitos legais, ou seja, são 'totalmente inviáveis'.

Certamente que esse não é um quadro exclusivo do Estado de Minas Gerais. Pelo contrário, ele caracteriza a maioria dos estados brasileiros, onde a tradição política é semelhante e com certeza, grande parte da América Latina.

Este panorama coloca em xeque a questão da autonomia municipal, da sustentabilidade econômica e social das cidades e das vantagens das crescentes responsabilidades confiadas às prefeituras e aos governos regionais.

Como se falar em sustentabilidade, em seu sentido mais amplo, daquilo que não tem sustentabilidade? A sustentabilidade defendida de maneira geral e irrestrita, pode significar uma perigosa anuência com um statu quo que, na realidade, precisa ser modificado e dinamizado, para permitir as mínimas condições de autonomia econômica e administrativa para as nossas cidades e municípios. Como já foi dito em linhas anteriores, este processo pode levar a uma generalização da autonomia com pobreza.

Todos desejamos cidades auto-sustentáveis, porém é preciso que elas tenham um total de população possível de sustentar as atividades econômicas; que tenham um sistema de arrecadação eficiente; que tenham um corpo de dirigentes e de funcionários capacitados para a gestão dos negócios públicos; que tenham canais de interação entre governo e comunidade efetivos e que pos- 
sam ofertar uma condição de vida razoável para os seus moradores.

Mais que isso, há de se mudar a estrutura de administração pública do país, na qual as decisões políticas e, principalmente, econômicas, ainda estão extremamente centralizadas pelo governo federal.

Sem essas condições, a sustentabilidade, em todos os níveis de administração pública, não passará de um discurso inteiramente apartado dos resultados práticos.

\section{Por uma gestão municipal responsável}

A luz destes antecedentes, parece ter ficado claro a difícil situação fiscal e administrativa da maioria dos municípios brasileiros, resultado de um processo historicamente desvirtuado e irresponsável, conduzido por uma comunidade que solicita a sua emancipação política a qualquer custo e autoridades políticas que fazem vista grossa e que autorizam estas emancipações.

O resultado é o que se relatou: uma multiplicação de prefeituras de minúsculas cidades, que arrecadam menos de $10 \%$ de suas receitas e cujos gastos geralmente superam a arrecadação, levando-os ao endividamento.

A falta crônica de recursos próprios, a má gestão política e econômica, e a complacência das autoridades do executivo, do legislativo e até mesmo do judiciário, criaram este panorama de completo descontrole das contas municipais.

O desequilíbrio fiscal, com gastos sistematicamente superiores às receitas, caracterizou a administração pública do Brasil, sem um controle rigoroso, até muito recentemente, com graves conseqüências econômicas (endividamento e carga tributárias, por exemplo) e sociais (deficiência dos serviços de saúde e educação, por exemplo).

Frente a este descontrole das finanças públicas em todos os níveis da administração pública brasileira, o governo criou a Lei de Responsabilidade Fiscal (LRF), uma accountability à brasileira, que é um instrumento para auxiliar e orientar os governantes a gerir os recursos públicos dentro de um marco de regras claras e precisas, aplicadas a todos os gestores de recursos públicos e em todas as esferas de governo, relativas à gestão da receita e da despesa públicas, ao endividamento e à gestão do patrimônio público. 
A LRF consagra a transparência da gestão como mecanismo de controle social, através da publicação de relatórios e demonstrativos de execução orçamentária, apresentando ao contribuinte a utilização dos recursos que ele coloca à disposição dos governantes.

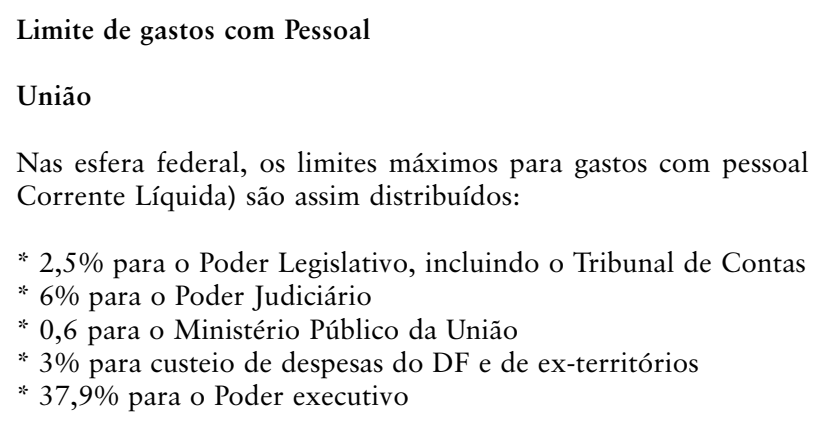
Corrente Líquida) são assim distribuídos:

* 2,5\% para o Poder Legislativo, incluindo o Tribunal de Contas

* 6\% para o Poder Judiciário

* 0,6 para o Ministério Público da União

* 3\% para custeio de despesas do DF e de ex-territórios

* 37,9\% para o Poder executivo

Nas esfera federal, os limites máximos para gastos com pessoal $(50 \%$ da receita

\section{Estados}

$\mathrm{Na}$ esfera estadual, os limites máximos para gastos com pessoal (60\% da receita Corrente Líquida) serão:

* 3\% para o Poder Legislativo, incluindo o Tribunal de Contas

* 6\% para o Poder Judiciário

* 2\% para o Ministério Público

49\% para o Poder Executivo

\section{Municípios}

Na esfera municipal, os limites máximos para gastos com pessoal ( $60 \%$ da receita Corrente Líquida) serão:

* 6\% para o Poder Legislativo, incluído o Tribunal de Contas, quando houver *54\% para o Poder Executivo

Além de fixar regras e limites para as despesas públicas, a LRF ainda determina que sejam criadas metas para controlar receitas e despesas. A "responsabilização" é severa e o governante que não cumprir a Lei estará sujeito a uma série de penalidades.

Há dois tipos de sanções: as institucionais, previstas na própria LRF, e as pessoais, previstas na Lei Ordinária que trata dos Crimes de Responsabilidade Fiscal como, por exemplo, a perda do cargo; a proibição de exercer emprego público; pagamento de multas e até a prisão. 
A LRF afeta aos governos da União, dos Estados, do Distrito Federal e dos Municípios, que a partir de agora estão se adaptando aos rigores legais, enquadrando as administrações ao novo código de conduta.

Neste primeiro momento, os municípios estão encontrando uma grande dificuldade para obedecer a LRF, o que tem gerado um alarme geral e muitas reclamações dos representantes municipais, relativamente a impossibilidade de obedecer o regulamento, o que é procedente, uma vez que nunca estiveram submetidos a um sistema de controle mais rígido.

A curto prazo, portanto, o rigor da Lei vai agravar a já complicada situação fiscal e administrativa da maioria dos municípios, e em especial dos pequenos, acostumados a um sistema de benevolência, de endividamento, de repasses intergovernamentais, de falta de controle de suas contas e de uma responsabilização mais rigorosa.

A médio e longo prazo se espera uma progressiva obediência a Lei e uma adequação das despesas às receitas, com uma natural depuração do quadro municipal do Brasil, tornando clara a inviabilidade de muitos municípios e a sobrevivência dos mais fortes.

\section{Conclusão}

Prestigiar os governos locais e as cidades, tornando-os auto-sustentáveis, não só é um princípio democrático, como também vem de encontro aos postulados básicos do modelo político-administrativo vigente na atualidade, no qual a descentralização é um imperativo.

Frente a esses novos paradigmas impositivos, os governos reformulam as suas normas legais, de forma a permitir o atendimento dos novos anseios de uma maior participação dos governos locais na estrutura política e econômica nacional.

Desta forma é possível estabelecer uma clara articulação entre a 'reforma do Estado', os processos de descentralização administrativa, e o novo papel que os municípios e cidades devem assumir neste novo contexto, quase que inquestionável, uma vez que sugere mais democracia, mais participação cidadã, e mais eficiência geral do sistema.

Este legítimo anseio de autonomia, aliado ao oportunismo de políticos nem sempre bem intencionados, cria a oportunidade para o surgimento de uma verdadeira 'indústria de municípios' 
no Brasil, quase sempre administrada sem critérios técnicos. Uma legislação imperfeita e guiada por critérios meramente políticos possibilita (e até estimula) a emancipação de uma quantidade enorme de pequenos municípios e cidades, sem o atendimento dos padrões de viabilidade legais exigidos.

Decorre daí, que aquilo de deveria ser, em tese, uma prática democraticamente saudável, acaba por se converter num processo político viciado, responsável pela insustentabilidade de várias administrações locais, sufocadas por compromissos e expectativas muito superiores da sua capacidade de gestão. Sem uma proposta real de descentralização e de reforma tributária, o processo de criação de novos municípios e cidades, pode potenciar todos os vícios que carrega e negar todas as virtudes que tem.

Depois de anos de permanência desta mentalidade irresponsável, que levou a este estado de insolvência municipal, o governo federal pressionado pelas novas regras internacionais que exigem um equilíbrio das contas públicas, promulgou uma 'Lei de Responsabilidade Fiscal" que normaliza os gastos nos três níveis de governo.

A aplicação desta lei já começa a trazer uma série de dificuldades para os municípios, acostumados aos gastos incontrolados, ao endividamento e às transferências de recursos. Existe um lado salutar neste caso, pois se espera que com o passar do tempo, os municípios façam uma adequação de suas despesas com as suas receitas limitando, entre outros, os gastos com pessoal, por exemplo.

No nosso entendimento é chegada a hora da verdade e da separação dos municípios realmente viáveis, daqueles que foram criados de forma artificial e que, em tese, terão que passar por um processo de revisão política-administrativa, aliás já prevista em lei, mas nunca concretizada.

\section{Bibliografía}

Bremaeker, F.E.J. (1996), "Limites à criação de novos Municípios: a Emenda Constitucional n. ${ }^{\circ} 15$ ", Revista de Administração Municipal, n. 219, abr./dez., Rio de Janeiro.

- (1995), "A evolução das finanças dos municípios brasileiros”, Revista de Administração Municipal, v. 42, n. 217, out./dez, Rio de Janeiro, pp.73-81. 
Carrión, M.F. (1999), Criterios para la descentralización, mimeo, Buenos Aires.

Carvalho, A. M. (2000), "La creación de ciudades no sustentables", Revista Contactar: La revista de los municipios, año II, núm. 5, Buenos Aires.

Constitução da República Federativa do Brasil (1991), Promulgada em 5 de outubro de 1998, Série Legislação Brasileira, São Paulo.

Fundação Getúlio Vargas (2000), Conjuntura Econômica, vol. 54, n. 5, maio, Rio de Janeiro.

Ministério do Planejamento, Orçamento e Gestão (s.d.), Gestão Fiscal Responsável, Brasília.

Jornal Estado de Minas (1999), Municípios à míngua, Caderno opinião, Belo Horizonte, 19/09/99, p.10.

Revista Veja (1999), Pequenos e Falidos, São Paulo, 07/07/1999, p. 124.

Enviado: 7 de marzo de 2002 Aceptado: 25 de marzo de 2002 